\title{
Optimization of Machining Process Parameters on Titanium Grade 9 using Taguchi Method
}

\author{
Raghavendra M J ${ }^{1}$, Dr. Ramachamdra $\mathrm{C} \mathrm{G}^{2}$, Mahammad Rafaz ${ }^{3}$, \\ Kripacharya Yadav ${ }^{4}$, Gonepnara Goneppa ${ }^{5}$, Sooraj R J ${ }^{6}$ \\ ${ }^{1}$ Assistant professor, Department of Mechanical Engineering, Srinivas Institute of Technology. \\ ${ }^{2}$ Professor, Department of Mechanical engineering, Presidency University. \\ 3,4,5,6 UG Students, Department of Mechanical Engineering, Srinivas Institute of Technology,
}

\begin{abstract}
In the contemporary world, the standard of the surface end is most significant demand for several turned work piece due to that maker's square measure seeking to stay competitive in the market. Taguchi parameter style is a powerful tool and efficient methodology for optimizing quality and performance output of the producing method. This paper investigates the parameters poignant the surface roughness manufacture in turning method for material Titanium Grade 5. Design of experiment was conducted for analysis of the influence of the turning parameters like spindle speed, feed, and depth of cut on Surface roughness. The results of the machining experiments for Titanium Grade 5 wherever wont to characterize the main factors poignant the surface roughness by the Analysis of Variance (ANOVA) methodology. The feed rate was found to be the foremost important parameter influencing the surface roughness in turning method. Confirmation check additionally has been performed to predict and verify the adequacy of the model for deciding optimum characteristics of respondents. The result obtained by on top of the methodology is going to be helpful to different analysis works for similar kind of study for any analysis on tool vibrations, cutting forces, rake angle etc.
\end{abstract}

Keywords: Surface Roughness, Titanium Grade 9, Taguchi method, ANOVA method

\section{INTRODUCTION}

Today, the manufacturing industry needs surface quality and productivity. The current state of the economy and consequent market pressure has forced manufacturers to simultaneously decrease the surface roughness and increase the metal removal rate so that they can meet the quality and time constraints. Mainly, the surface roughness affects wear resistance, ductility, tensile strength, fatigue strength, etc., for machined parts and cannot be neglected in designing any component. The imperative objective of the science of metal cutting is the solution of practical problems associated with the efficient and precise removal of metal from the work piece. Turning process is used in the experimentation. Turning is one of the common metal cutting operations used for machining parts in the manufacturing industry. The demand for high quality and fully automated production focuses attention on the surface condition of the product, especially the roughness of the machined surface, because of its effect on product appearance, function, and reliability. In the present work, an experimental investigation of machining parameters on Titanium Grade 9 with HSS tool in turning is carried out and the effect of different cutting parameters on the surface roughness is studied because one can relate quality with surface roughness and productivity. The material used for the analysis is Titanium Grade 5 which is widely used in Shaft pump valves, my ladder rungs, Gas turbines, Pipes flanges \& fitting for the oil industry, Nut and bolt. Obtained experimental readings are analyzed with the help of the Taguchi method and ANOVA. Results obtained from both this analysis are closely matching with each other. Traditionally, the selection of cutting conditions for metal cutting is left to the machine operator. In such cases, the experience of the operator plays a major role, but even for a skilled operator, it is very difficult to attain the optimum values each time. Machining parameters in metal turning are cutting speed, feed rate and depth of cut. The setting of these parameters determines the quality characteristics of turned parts. Hence our aims to study the effect of changes in parameter over the surface finish of the material. Also to get different combinations of parameters in order to get a good surface finish. During going through the process we will study the Taguchi Method and to find the expected result by least possible no. of the experiment.

TABLE 1 Independent variables and their levels.

\begin{tabular}{|c|c|c|c|c|c|}
\hline $\mathrm{Al}$ & $\mathrm{Fe}$ & $\mathrm{Mn}$ & No & $\mathrm{V}$ & $\mathrm{Ti}$ \\
\hline 6.32 & 0.50 & 0.05 & 1 & 4.12 & 87.96 \\
\hline
\end{tabular}

Additionally, Sun et al. [2] examined the process of dry-turning Ti-3Al-4V alloy. They also pointed out that the cutting force reduced dramatically when the cutting speed was higher than $113 \mathrm{~m} / \mathrm{min}$ because of the thermal softening of work piece materials. Referring the table nol to evaluate the variation of cutting temperature, Li et al. [3] investigated the high-speed milling of Ti-3Al-4V using uncoated K10 carbide. They proposed a method to measure cutting temperature. Based on the measurement of cutting temperature, the effect of cutting speed on the cutting temperature was investigated. The results showed that cutting temperature increased with cutting speed, and no reduction of cutting temperature at higher cutting speed was observed. Same results were obtained from studies of the tool face temperature which changed with cutting speed in the machining of Ti-31-4V [4,5,8]. 


\section{RESULTS AND DISCUSSIONS}

The experimental test was conducted on the basis of the Taguchi's L9 orthogonal array system with the help of Minitab soft wear. The table no 2 and table no 3 at which shows the different cutting input parameters for machining of Titanium grade-9 material with PVD coated carbide inserts. The output response which obtained from the turning operations of titanium bar is tabulated in the table no 4 with corresponding $\mathrm{S} / \mathrm{N}$ ratio.

TABLE 2. Independent variables and their levels

\begin{tabular}{|c|c|c|c|}
\hline \multirow{2}{*}{ Levels } & Cutting Speed & Feed Rate & Depth of cut \\
\cline { 2 - 4 } & $\mathbf{V}_{\mathbf{c}}(\mathbf{m} / \mathbf{m i n})$ & $\mathbf{f}(\mathbf{m m} / \mathbf{r e v})$ & $\mathbf{a}_{\mathbf{p}}(\mathbf{m m})$ \\
\hline 1 & 30 & 0.046 & 0.1 \\
\hline 2 & 40 & 0.093 & 0.15 \\
\hline 3 & 50 & 0.125 & 0.2 \\
\hline
\end{tabular}

TABLE 3. Input Parameters

\begin{tabular}{|c|c|c|c|c|c|c|c|c|c|}
\hline Sl. No. & $\mathbf{1}$ & $\mathbf{2}$ & $\mathbf{3}$ & $\mathbf{4}$ & $\mathbf{5}$ & $\mathbf{6}$ & $\mathbf{7}$ & $\mathbf{8}$ & $\mathbf{9}$ \\
\hline $\mathbf{a}_{\mathbf{p}}$ & 0.1 & 0.1 & 0.1 & 0.15 & 0.15 & 0.15 & 0.2 & 0.2 & 0.2 \\
\hline $\mathbf{V}_{\mathbf{c}}$ & 30 & 40 & 50 & 30 & 40 & 50 & 30 & 40 & 50 \\
\hline $\mathbf{f}$ & 0.1 & 0.15 & 0.2 & 0.1 & 0.15 & 0.2 & 0.1 & 0.15 & 0.2 \\
\hline
\end{tabular}

Analysis of $\mathrm{S} / \mathrm{N}$ ratio

Signal to noise ratio is to measure used in the engineering system. That compares the level of the desired signal to the noise ratio. The Taguchi's orthogonal array techniques are used to measure the input values for the optimum solutions and signal to noise ratio is to be larger values. There will be three characteristics like i) smaller the better, ii) larger the better and iii) nominal is better.in this experiments, cutting force, surface roughness is mapped by using quality characteristics like smaller the better.

$$
\frac{S}{N}=-10 \log \frac{1}{n}\left(\sum y^{2}\right)
$$

Where $\mathrm{y}$ is the measured value and $\mathrm{n}$ is the number experimental test conduct in which input parameters having high signal to noise ratio which gives the least variance and quality of the system.

TABLE 4 Output Response and S/N ratio for PVD

Coated Cutting Tool Insert

\begin{tabular}{|c|c|c|c|c|c|c|c|}
\hline \multirow[b]{2}{*}{ Sl No } & \multicolumn{3}{|c|}{ Input } & \multicolumn{2}{|c|}{ Output Response } & \multicolumn{2}{|c|}{ S/N Ratios } \\
\hline & ap & Vc & f & $\mathbf{R a}$ & $\mathbf{F z}$ & $\mathbf{R a}$ & $\mathbf{F z}$ \\
\hline 1 & 0.04 & 30 & 0.1 & 2.53 & 164.85 & -8.06 & -44.34 \\
\hline 2 & 0.04 & 40 & 0.15 & 3.26 & 173.01 & -10.26 & -44.76 \\
\hline 3 & 0.04 & 50 & 0.2 & 4.77 & 186.15 & -13.57 & -45.40 \\
\hline 4 & 0.1 & 30 & 0.15 & 2.77 & 368.68 & -8.85 & -51.33 \\
\hline 5 & 0.1 & 40 & 0.2 & 3.06 & 296.66 & -9.71 & -49.45 \\
\hline 6 & 0.1 & 50 & 0.1 & 4.09 & 153.66 & -12.23 & -43.73 \\
\hline 7 & 0.15 & 30 & 0.2 & 2.69 & 283.8 & -8.60 & -49.06 \\
\hline 8 & 0.15 & 40 & 0.1 & 3.88 & 153.24 & -11.78 & -43.71 \\
\hline 9 & 0.15 & 50 & 0.15 & 4.99 & 220.8 & -13.96 & -46.88 \\
\hline
\end{tabular}

\section{Analysis of Variance (ANOVA)}

The individual process parameters will be determined by using ANOVA Minitab soft wear. The table no 5 ANOVA is techniques which investigate the effect of machining process parameters and in Taguchi's technique cannot trust for determining the effect of individual process parameters will be in percentage contribution and some of the factors influence the design model. The ANOVA table 5 is consists of sum squares (SS), mean squares (MS), the degree of freedom (DOF), P-value, Fvalue and percentage contribution

Analyses of Variance (ANOVA) for coated tool insert machining with titanium grade-9

TABLE 1 Analysis of Surface Roughness $\left(\mathrm{R}_{\mathrm{a}}\right)$

\begin{tabular}{|l|l|l|l|l|l|l|}
\hline \multicolumn{1}{|c|}{ Source } & \multicolumn{1}{|c|}{ DF } & \multicolumn{1}{|c|}{ SS } & \multicolumn{1}{|c|}{ MS } & \multicolumn{1}{c|}{ P } & \% \\
\hline ap & 2 & 2.1824 & 1.092 & 1.22 & 0.45 & 5.7 \\
\hline Vc & 2 & 34.063 & 17.0315 & 19.06 & 0.05 & 88.92 \\
\hline f & 2 & 0.2748 & 0.1374 & 0.15 & 0.867 & \\
\hline Error & 2 & 1.7871 & 0.8935 & & & \\
\hline Total & 8 & 38.3072 & & & & \\
\hline
\end{tabular}


TABLE 6 Analysis of Cutting Force (Fz)

\begin{tabular}{|c|c|c|c|c|c|c|}
\hline Source & DF & Adj SS & Adj MS & F-Value & P-Value & \% Cont \\
\hline ap & 2 & 16.701 & 8.350 & 8.32 & 0.107 & $\mathbf{2 6 . 4 7}$ \\
\hline Vc & 2 & 14.034 & 7.017 & 6.99 & 0.125 & 22.25 \\
\hline f & 2 & 30.346 & 15.173 & 15.11 & 0.062 & 48.1 \\
\hline Error & 2 & 2.008 & 1.004 & & & 3.18 \\
\hline Total & 8 & 63.09 & & & & 100 \\
\hline
\end{tabular}

From the ANOVA table, from the table no 5 the speed which contributes the $88.92 \%$ which is the most significant cutting parameters which influence on the surface roughness and followed by the depth of cut at 5.7\%. However, the feed rate at least efficacy of $0.72 \%$ which controlling the surface roughness of the materials and it is also not statistically significant to influence.

From the ANOVA table no 6 shows that the P-value of feed rate is 0.062 which are very less than the 0.1 . It shows that depth of cut which influences significantly on the cutting force on the tool. The depth of cut and cutting speed which has been contributing more on the tool is $26.47 \%$ and $22.25 \%$ but the biggest contribution came from the feed rate is about $48.1 \%$ which is not significant. The contribution of error is $4.67 \%$ and $3.18 \%$ for surface roughness and cutting force respectively.

\section{Mean Effect Plots}

For the analysis, the data to study the amount of cutting parameters and the main effect plots on the surface roughness were analyzed. With the help of Minitab soft wear shows the variation of individual responsibility with three machining parameters separately. In the plots, $\mathrm{X}$-axis indicates the values of cutting machining parameters and $\mathrm{Y}$-axis denotes the response value. The plots are used to find the design condition for surface roughness.

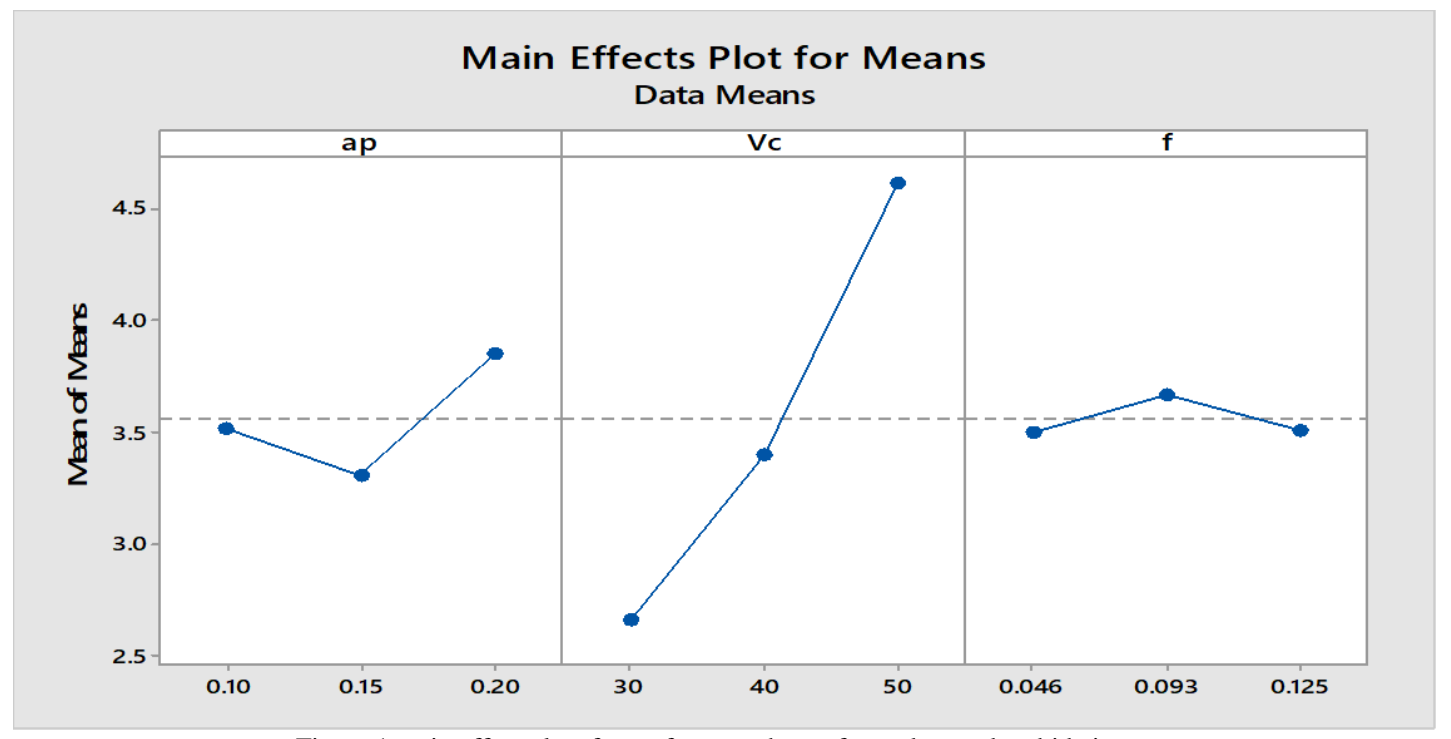

Figure 1 main effect plots for surface roughness for pvd coated carbide insert

Figure 1 shows that the MEP for surface roughness, the graph shows that increase the depth of cut significantly roughness also increases in smaller rate, but when the speed increases there will be continuous increases in surface roughness. A feed rate increases there is decrease the surface roughness. 


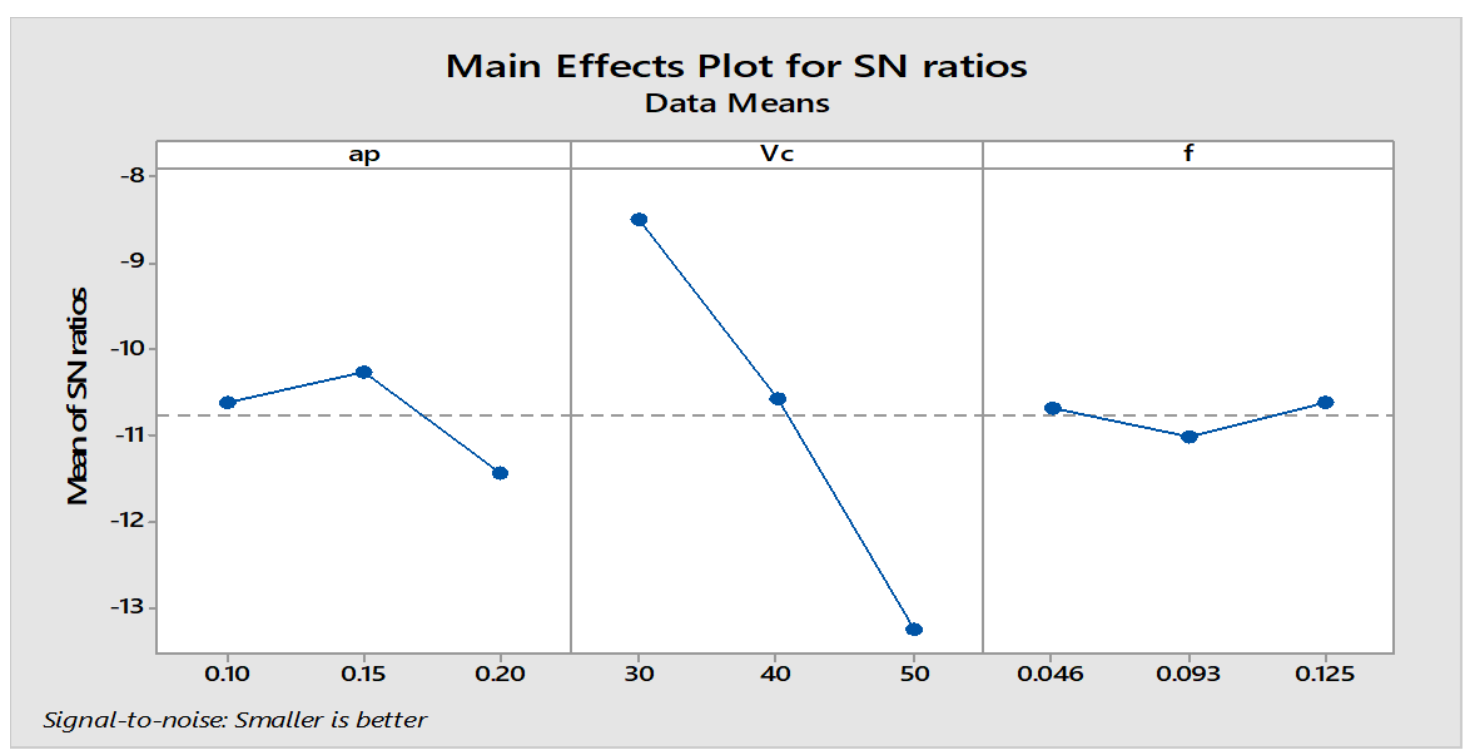

Figure 2 surface roughness based on the $\mathrm{s} / \mathrm{n}$ ration for pvd coated carbide tool

Figure 2 and 3 shows that the S/N Ration for surface roughness, the graph shows that increase the depth of cut significantly roughness also decreases, but when the speed increases there will be continuous fall down in surface roughness. A feed rate increases there is increases the surface roughness.
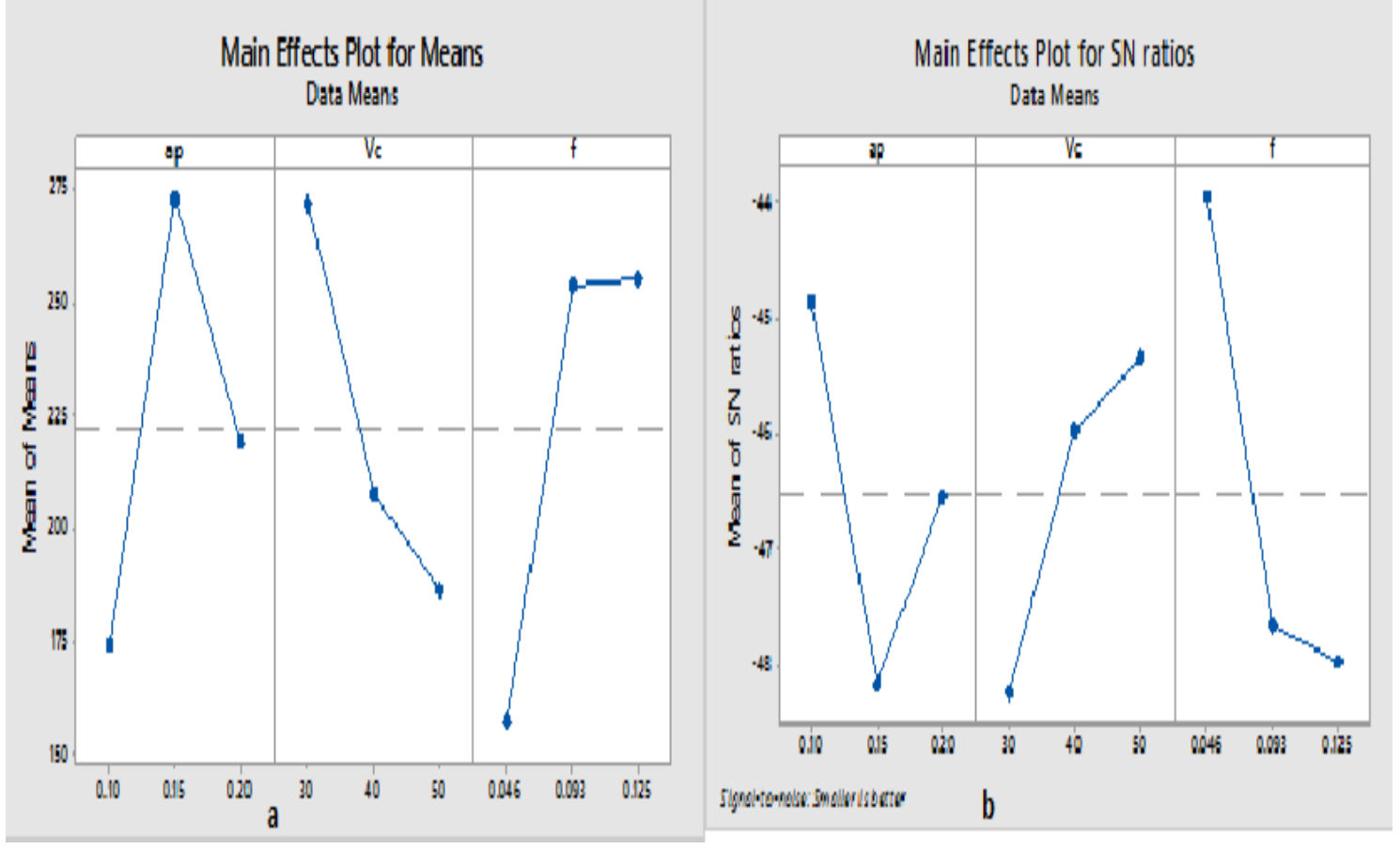

Figure 3 Main effect plots (a) and S/N ratio (b) for cutting force for PVD coated carbide Insert

\section{CONCLUSIONS}

Taguchi technique of experimental style has been applied for investigation multi response method parameter for turning Titanium Grade 5 with L9 orthogonal array. Results obtained from Taguchi technique are closely matches with analysis of variance. Best parameter found for finished surface are: spindle speed $340 \mathrm{rpm}$; feed $0.2 \mathrm{~mm} / \mathrm{rev}$; depth of cut $0.3 \mathrm{~mm}$. The parameter found for rough surface are cutting speed $340 \mathrm{rpm}$; depth of cut zero. $3 \mathrm{~mm}$; feed $0.2 \mathrm{~mm} / \mathrm{rev}$. Also parameter for optimum combination gives minimum surface roughness and that confirms the take a look at of minimum surface roughness. For the compromising value from Analysis of variance for $\mathrm{S} / \mathrm{N}$ ratios, the $\mathrm{F}$ value of parameters is spindle speed 2.95; feed 144.51; depth of cut 12.55. Hence feed is most influencing parameters corresponding to the quality characteristics of surface roughness. Taguchi gives systematic simple approach and economical technique for the optimum in operation conditions. The confirmation test shows that min value of surface roughness for Titanium Grade 5 as $1.91 \mu \mathrm{m}$ 


\section{REFERENCES}

[1] Boyer RR (1995) Titanium for aerospace: rationale and applications.

[2] Adv Perform Mater 2:349-368. doi:10.1007/BF00705316

[3] Peters M, Kumpfert J, Ward CH, Leyens C (2003) Titanium alloys for aerospace applications. Adv Eng Mater 5:419-427. doi:10.1002/ adem.200310095

[4] Schauerte O (2003) Titanium in automotive production. Adv Eng Mater 5:411-418. doi:10.1002/adem.200310094

[5] Hartman AD, Gerdemann SJ, Hansen JS (1998) Producing lower-cost titanium for automotive applications. JOM 50:16-19. doi:10. 1007/s11837998-0408-1

[6] Treves C, Bruni S, Martinesi M, Stio M, Bacci T, Borgioli F (2005) Effects of surface treatment of Ti-6Al-4V titanium alloy on biocompatibility in cultured human umbilical vein endothelial cells. Acta Biomater 1:223-234. doi:10.1016/j.actbio.2004.11.001

[7] Yeung KWK, Wu SL, Zhao Y, Liu XM, Kao RYT, Luk KDK, Cheung KMC, Chu PK (2013) Antimicrobial effects of oxygen plasma modified medical grade Ti-6Al-4V alloy. Vacuum 89:271-279. doi:10.1016/j.vacuum.2012.07.014

[8] Rahman M, Wang ZG, Wong YS (2006) A review on high-speed machining of titanium alloys. JSME Int J 49:11-20. doi:10.1299/ jsmec.49.11

[9] Ezugwu EO, Wang ZM (1997) Titanium alloys and their machinability-a review. J Mater Process Technol 68:262-274. doi:10.1016/S09240136(96)00030-1

[10] Raghavendra M J \& Dr. Ramachandra C G, “A study on Different Tool Condition Monitoring System Available to Monitor Tool-Flank Wear", International Journal of Engineering Trends and Technology (IJETT), Spl. Issue, p-ISSN: 2349-0918, e-ISSN: 2231-5381, pp.359-364..

[11] 10. Raghavendra M J and Dr. Ramachandra C G, "Determination of Flak Wear of a PVD Coated Carbide Tool by Condition Monitoring", Journal of Engineering Technological Research (JETR) ISSN: 2229-9262, Volume No.8, March 2017 Page No.108-113. 